\title{
Audit of Obstetric Outcome in Morbidly Obese Women at Great Western Hospital NHS Foundation Trust UK
}

\author{
Emmanuel Ekanem, Lalrinawmi Lalrinawmi \\ Department of Obstetrics and Gynaecology, Great Western Hospital NHS Foundation Trust, \\ Swindon, UK \\ Email: Emmanuel.Ekanem@nhs.net
}

How to cite this paper: Ekanem, E. and Lalrinawmi, L. (2020) Audit of Obstetric Outcome in Morbidly Obese Women at Great Western Hospital NHS Foundation Trust UK. Open Access Library Journal, 7: e6298.

https://doi.org/10.4236/oalib.1106298

Received: April 4, 2020

Accepted: April 26, 2020

Published: April 29, 2020

Copyright (๑) 2020 by author(s) and Open Access Library Inc.

This work is licensed under the Creative Commons Attribution International License (CC BY 4.0).

http://creativecommons.org/licenses/by/4.0/

\begin{abstract}
Obesity in pregnancy is a substantial public health problem with potentially dire consequences on pregnancy outcome for the mother and the neonate. Objective: To determine the prevalence and care of morbidly obese women $\left(\mathrm{BMI}>40 \mathrm{~kg} / \mathrm{m}^{2}\right)$ in our obstetric population over one year against standards and criteria set by the Royal College of Obstetricians and Gynaecologists (RCOG) in the Green-top Guideline No. 72 "Care of women with Obesity in pregnancy". Methods: This was a retrospective longitudinal cohort study conducted at the obstetrics department of Great Western Hospital NHS Foundation Trust UK. Data were collected from patients' records on Medway Maternity software and hospital notes of women with BMI $>40 \mathrm{~kg} / \mathrm{m}^{2}$ who delivered between $1^{\text {st }}$ December 2017 and $31^{\text {st }}$ December 2018. Data were analyzed using Epi info version 7.0. Results were presented in tables and charts. Results: During the period of the audit, there were a total of 4198 deliveries. The number of morbidly obese women was 145 , giving a prevalence of $3.45 \%$. Majority of the women (42) had no prepregnancy complications. Complications before pregnancy were previous miscarriages, polycystic ovarian syndrome, disc pro-lapse, diabetes, previous IUGR and hyperprolactinaemia. Antenatally, most patients had no complications. Gestational hypertension was the most common complication (9), followed by gestational diabetes (7), intrauterine growth restriction (1), placenta praevia (1), and severe preeclampsia (1). None of the patients had intrapartum complications in this study. Majority of the patients (46) had no postpartum complications, 11 had postpartum haemorrhage, 2 had postpartum hypertension, and one had wound infection and dehiscence. Compliance with care was $92.67 \%$. Conclusion: This audit revealed that morbidly obese women in our obstetric population were at risk of some of the complications of obesity in pregnancy, labour, delivery and postpar-
\end{abstract}


tum. The care for these women was within recommended standards with room for improvement.

\section{Subject Areas}

Obstetrics \& Gynaecology

\section{Keywords}

Pregnancy, Obesity, Body Mass Index (BMI)

\section{Introduction}

The World Health Organization (WHO) "World Report" asserts that obesity is a global health problem. Throughout the globe, one thousand two hundred million people have problems related to overweight or obesity and epidemiological studies reveal that $22 \%$ of the adult population is obese [1]. In the UK population obesity has become one of the most commonly occurring risk factors in obstetrics, with $21.3 \%$ of the women in the antenatal population being obese and just under one-half of the pregnant population (47.3\%) having a body mass index (BMI) within the normal range $\left(18.5 \mathrm{~kg} / \mathrm{m}^{2}\right.$ to $\left.24.9 \mathrm{~kg} / \mathrm{m}^{2}\right)$. Obesity is classified according to the World Health Organization (WHO) as follows: Underweight $<18.5 \mathrm{~kg} / \mathrm{m}^{2}$, normal range $18.5-24.9 \mathrm{~kg} / \mathrm{m}^{2}$, overweight $\geq 25.0-29.9 \mathrm{~kg} / \mathrm{m}^{2}$, class I obesity $30.0-34.9 \mathrm{~kg} / \mathrm{m}^{2}$, class II obesity $35.0-39.9 \mathrm{~kg} / \mathrm{m}^{2}$, class III obesity $\geq 40.0 \mathrm{~kg} / \mathrm{m}^{2}$ [2]. Table 1 below describes the classification of obesity.

Obesity has implications in pregnancy, labour and delivery, as well as foetal and neonatal period and this audit, aims to identify these specific outcomes in morbidly obese women.

\section{Aim}

To determine the foetal, neonatal and maternal outcome in morbidly obese women $\left(\mathrm{BMI}>40 \mathrm{~kg} / \mathrm{m}^{2}\right)$.

Table 1. Classification of obesity [2].

\begin{tabular}{cc}
\hline Classification & BMI $\left(\mathrm{kg} / \mathrm{m}^{2}\right)$ \\
\hline Under weight & $<18.5$ \\
Normal weight & $18.5-24.9$ \\
Over weight & $25.0-29.9$ \\
Mild or Class I & $30.0-34.9$ \\
Moderate or Class II & $35.0-39.9$ \\
Severe of Class III & $\geq 40.0$ \\
\hline
\end{tabular}




\section{Objectives}

1) To assess the prevalence of morbid obesity in women in our obstetric population over one year.

2) To determine the common foetal and neonatal complications in morbidly obese women.

3) To identify the common maternal complications in morbidly obese women.

\section{Audit Criteria and Standards}

The criteria were from the RCOG Green-top Guideline no 72 "Care of women with Obesity in pregnancy" with standards being a hundred percent [2].

\section{Materials and Methods}

This was a retrospective longitudinal cohort study carried out at the Obstetrics department of Great Western Hospital NHS Foundation Trust.

Included in this audit were all pregnant women with BMI $>40 \mathrm{~kg} / \mathrm{m}^{2}$ who either had a vaginal delivery or caesarean section between 24 weeks and 42 completed weeks during the period of $1^{\text {st }}$ December 2017 to $31^{\text {st }}$ December 2018. Excluded from this audit were women with BMI $<40 \mathrm{~kg} / \mathrm{m}^{2}$. The sample was randomly chosen from patients' records on Medway maternity software, and hospital notes and 60 case notes were selected and studied. Using a specially designed data collection form, the information that was gathered after a thorough review of Medway Maternity software and case records included socio-demographic characteristics of the patients consisting of hospital number, age, ethnicity, parity, marital status, and last menstrual period. Antenatal indices included expected date of delivery, gestational age in weeks, booking weight, booking BMI, prepregnancy complication and details of prenatal care. Data regarding antepartum complications, delivery details, intrapartum complications and postpartum complications were also gathered. Data of neonatal outcome were sex, Apgar scores, birth weight, antenatal, intrapartum and postnatal complications. The data obtained were compared with the criteria and standards from RCOG Green-top Guideline no 72 "Care of women with Obesity in pregnancy". Data were analyzed using Epi info version 7.0 statistical package. Results were presented in tables and charts. Ethical approval was sort, and the study was approved by the clinical lead of obstetrics and gynaecology and clinical audit and effectiveness team of Great Western Hospital NHS Foundation Trust, UK.

\section{Results}

During the period of the audit from $1^{\text {st }}$ December 2017 to $31^{\text {st }}$ December 2018, there were a total of 4198 deliveries. The number of morbidly obese women was 145 , giving a prevalence of $3.45 \%$.

Table 2 represents the age distribution. Most of the parturient with BMI $>40$ $\mathrm{kg} / \mathrm{m}^{2}$ were in the age range of $30-35(40 \%)$, and the least number of morbidly obese women were aged $20-24$ (10\%). 
Table 3 outlines the parity distribution. Nulliparous women were more likely to be morbidly obese (38.33\%) followed by primiparous women (31.67\%). Women in their fourth pregnancy were least likely to be morbidly obese (3.33\%).

Table 4 shows the distribution of prepregnancy complications. Majority of the women (42) had no prepregnancy complications (42), and of the remaining 18 women, 12 had previous miscarriages (20\%), 2 had a diagnosis of polycystic ovarian syndrome before pregnancy (3.33\%) while the remaining had 1 of the following (1.67\%)-disc prolapse, diabetes, previous intrauterine growth restriction (IUGR) and hyperprolactinaemia.

Table 2. Age distribution.

\begin{tabular}{ccc}
\hline Variable & Frequency & Percentage (\%) \\
\hline Age (Years) & 0 & 0.00 \\
\hline$<20$ & 6 & 10.00 \\
$20-24$ & 20 & 33.33 \\
$25-29$ & 24 & 40.00 \\
$30-34$ & 10 & 16.67 \\
$>35$ & 60 & 100 \\
Total & &
\end{tabular}

Table 3. Parity distribution.

\begin{tabular}{ccc}
\hline Variable & Frequency & Percentage (\%) \\
\hline Parity & 23 & 31.67 \\
\hline 0 & 19 & 31.67 \\
1 & 11 & 18.33 \\
2 & 5 & 8.33 \\
3 & 2 & 3.33 \\
4 & 60 & 100 \\
\hline
\end{tabular}

Table 4. Prepregnancy complications.

\begin{tabular}{cccc}
\hline Variable & Frequency & Percentage (\%) \\
\cline { 1 - 2 } Prepregnancy complications & & 2 & 70.00 \\
None & 12 & 20.00 \\
Previous miscarriages & 2 & 3.33 \\
PCOS & 1 & 1.67 \\
Disc prolapse & 1 & 1.67 \\
Diabetes & 1 & 1.67 \\
Previous IUGR & 1 & 1.67 \\
Hyperprolactinaemia & 60 & 100 \\
Total & &
\end{tabular}


Figure 1 represents antepartum complications. In the antenatal period, most patients (42) had no complications. Gestational hypertension was the most common complication (9), followed by gestational diabetes (7), intrauterine growth restriction (1), placenta praevia (1), and severe preeclampsia (1).

Table 5 reveals the intrapartum characteristics. Regarding mode of delivery, thirty women had a normal vaginal birth, twenty-eight had a caesarean delivery, and two had a forceps delivery. For intrapartum complications, none of the patients had intrapartum complications in this study.

Figure 2 shows postpartum complications. Majority of the patients (46) had no postpartum complications, 11 had a postpartum haemorrhage, 2 had postpartum hypertension, and one had wound infection and dehiscence.

\section{Antepartum complications}

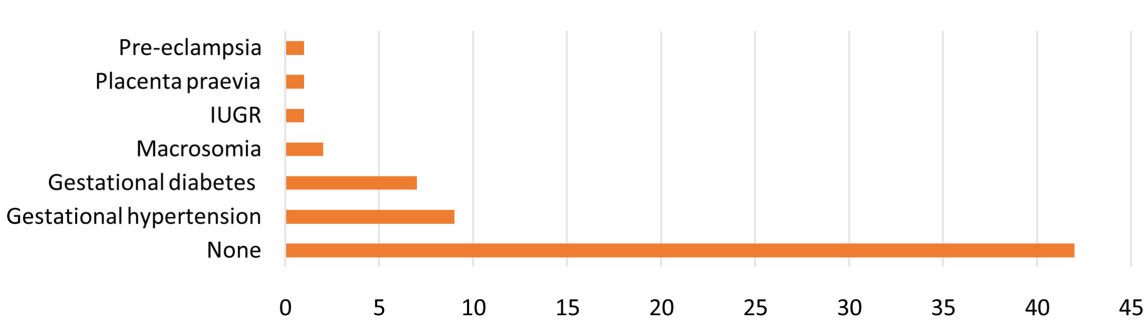

Figure 1. Antepartum complications.

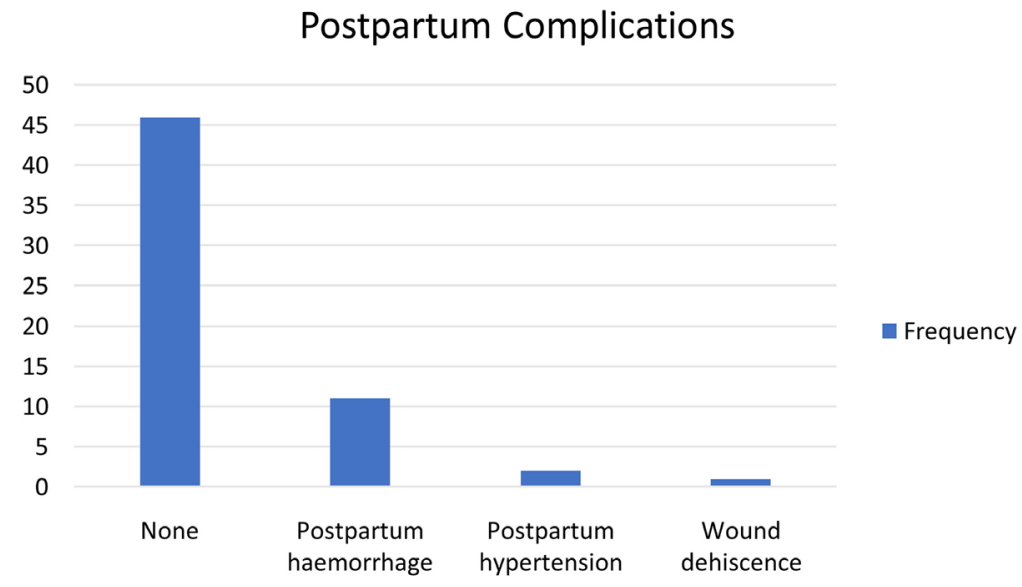

Figure 2. Postpartum complications.

Table 5. Intrapartum characteristics.

\begin{tabular}{lcc}
\hline \multicolumn{1}{c}{ Variable } & Frequency & Percentage (\%) \\
\hline Mode of delivery & 30 & \\
Normal & 28 & 50.00 \\
Caesarean section & 2 & 46.67 \\
Forceps & 60 & 3.33 \\
Total & & 100 \\
Intrapartum complications & 60 & 100 \\
None & 60 \\
\hline
\end{tabular}


Table 6 represents the neonatal outcome and gestational age at delivery. Thirty-six of the neonates were girls, and twenty-four were boys. Fifty-seven of the babies had a $5^{\text {th }}$ minute Apgar score of more than seven, and two had $5^{\text {th }}$ minute Apgar scores between four and six and one baby had a $5^{\text {th }}$ minute Apgar score of zero. Forty-eight of the babies had an average birth weight, and eleven were macrosomic, and one baby had a low birth weight. Most women (88.33\%) delivered between 37 weeks and 41 weeks six days, followed by women 10\%) who were less than 37 weeks. Only one woman (1.67\%) delivered after 42 weeks.

Figure 3 shows the foetal and neonatal complications discovered during the audit period. Seventy-seven per cent had no complications; eighteen per cent were macrosomic, congenital anomaly in three per cent and stillbirth in two per cent of babies.

Table 7 reveals audit standards and result. After comparing the criteria and standards with the auditable standards in the RCOG guidelines, it was found that the hospital was $92.67 \%$ compliant with the recommended standards for patient care.

Table 6. Neonatal outcome and gestational age at delivery.

\begin{tabular}{lcc}
\hline \multicolumn{1}{c}{ Variable } & Frequency & Percentage (\%) \\
\hline Sex & 24 & \\
Boy & 36 & 40.00 \\
Girl & 60 & 60.00 \\
Total & & 100 \\
$5^{\text {TH }}$ minute Apgar scores & 1 & \\
0 & 2 & 1.67 \\
$4-6$ & 57 & 3.33 \\
$7-10$ & 60 & 95.00 \\
Total & & 100 \\
Birth weight in kg & 1 & \\
$<2.5$ & 48 & 1.67 \\
$2.5-4.0$ & 11 & 80.00 \\
$>4.0$ & 60 & 18.30 \\
Total & & 100 \\
Gestational age (weeks) & & 1.67 \\
$<37$ & 60 & 100 \\
$37-41^{+6}$ & 63 & \\
$\geq 42$ & 53.33 \\
Total & 1 & \\
\hline & & \\
\hline
\end{tabular}


Table 7. Audit standards and results.

\begin{tabular}{|c|c|c|c|c|c|c|}
\hline Criteria & & Standards & Number $\mathbf{n}$ & Exceptions & Compliance \% & Re-Audit \\
\hline 1 & $\begin{array}{l}\text { Availability of local } \\
\text { policy and } \\
\text { guidelines about } \\
\text { the care of obese } \\
\text { women in } \\
\text { pregnancy }\end{array}$ & 100 & 60 & Nil & 100.00 & \\
\hline 2 & $\begin{array}{l}\text { Received } \\
\text { information about } \\
\text { risk of obesity in } \\
\text { pregnancy }\end{array}$ & 100 & 60 & Nil & 100.00 & \\
\hline 3 & $\begin{array}{l}\text { Measurement of } \\
\text { weight at booking } \\
\text { and } 36 \text { weeks }\end{array}$ & 100 & 54 & Nil & 90.00 & \\
\hline 4 & $\begin{array}{l}\text { The proportion } \\
\text { that received } \\
\text { folic acid }\end{array}$ & 100 & 60 & Nil & 100.00 & \\
\hline 5 & $\begin{array}{l}\text { Proportion that } \\
\text { received vitamin } \mathrm{D}\end{array}$ & 100 & 58 & Nil & 96.67 & \\
\hline 6 & $\begin{array}{l}\text { Commencement of } \\
\text { Aspirin }\end{array}$ & 100 & 57 & Nil & 95.00 & \\
\hline 7 & Antenatal screening & 100 & 60 & Nil & 100.00 & \\
\hline 8 & Screening for GDM & 100 & 60 & Nil & 100.00 & \\
\hline 9 & $\begin{array}{l}\text { Screening for } \\
\text { hypertension }\end{array}$ & 100 & 60 & Nil & 100.00 & \\
\hline 10 & $\begin{array}{l}\text { Screening for } \\
\text { mental health } \\
\text { problems }\end{array}$ & 100 & 60 & Nil & 100.00 & \\
\hline 11 & Anaesthetic referral & 100 & 53 & Nil & 88.33 & \\
\hline 12 & $\begin{array}{l}\text { Intrapartum } \\
\text { surveillance }\end{array}$ & 100 & 60 & Nil & 100.00 & \\
\hline 13 & $\begin{array}{l}\text { Intrapartum } \\
\text { multidisciplinary } \\
\text { care- }\end{array}$ & 100 & 60 & Nil & 100.00 & \\
\hline 14 & $\begin{array}{l}\text { Induction of } \\
\text { labour offered }\end{array}$ & 100 & 30 & Nil & 100.00 & \\
\hline 16 & $\begin{array}{l}\text { Caesarean section } \\
\text { offered }\end{array}$ & 100 & 30 & Nil & 100.00 & \\
\hline 16 & $\begin{array}{l}\text { Support for } \\
\text { breastfeeding }\end{array}$ & 100 & 60 & Nil & 100.00 & \\
\hline \multirow[t]{2}{*}{17} & $\begin{array}{l}\text { Contraception } \\
\text { advice }\end{array}$ & 100 & 60 & Nil & 100.00 & \\
\hline & & & & $\begin{array}{c}\text { Overall } \\
\text { compliance }\end{array}$ & 92.67 & \\
\hline
\end{tabular}




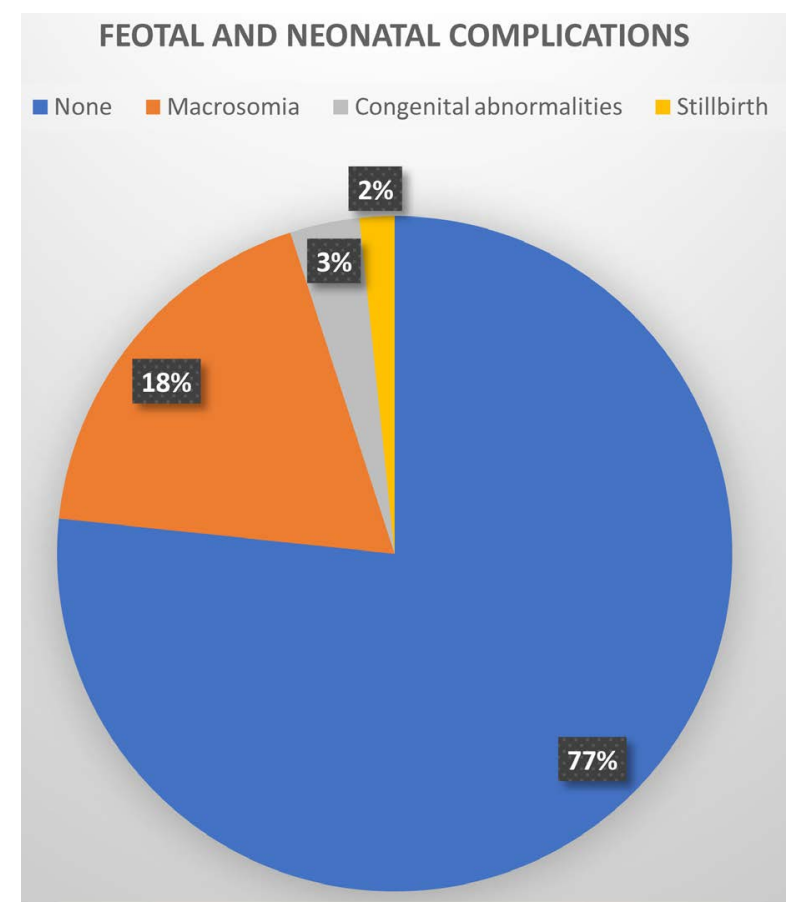

Figure 3. Foetal and neonatal complications.

\section{Discussion}

Obesity is defined as having a body mass index (BMI) higher than $30 \mathrm{~kg} / \mathrm{m}^{2}$. It is considered by the World Health Organization (WHO) as a huge public health problem with significant and far-reaching implications to mother and baby [3] [4]. The percentage of obesity in adults in the UK is on a steady climb, and the prevalence of obesity is between $24.7 \%$ and $24.9 \%$ [5]. Also, a large Scottish maternity hospital-based study observed a two-fold increase in the proportion of women with a booking BMI of $30 \mathrm{~kg} / \mathrm{m}^{2}$ over the last decade [6].

WHO standardizes the classification of weight according to body mass index (BMI). Further, it categorizes this into normal BMI being18.5 - $24.9 \mathrm{~kg} / \mathrm{m}$, overweight defined as a BMI of $\geq 25 \mathrm{~kg} / \mathrm{m}^{2}$ but $<30 \mathrm{~kg} / \mathrm{m}^{2}$ and obesity as BMI $>30$ $\mathrm{kg} / \mathrm{m}^{2}$. Obesity is further subdivided into class 1 , class 2 and class 3 or morbid obesity as follows: obese class I $30.0-34.9 \mathrm{~kg} / \mathrm{m}^{2}$, obese class II $35.00-39.9$ $\mathrm{kg} / \mathrm{m}^{2}$ and obese class III $\geq 40.0 \mathrm{~kg} / \mathrm{m} \mathrm{[2]} \mathrm{[4]} \mathrm{[7].} \mathrm{This} \mathrm{is} \mathrm{shown} \mathrm{in} \mathrm{Table} 1 . \mathrm{Nu}-$ merous studies have documented the increasing burden of obesity in pregnancy and its adverse foetal, neonatal and maternal outcome. Maternal outcomes include gestational hypertension, gestational diabetes, preeclampsia, abruptio placentae, disseminated coagulopathy/HELLP syndrome, slow labour, induced labour, increased risk of caesarean section, shoulder dystocia, pulmonary oedema/ aspiration, acute renal failure, eclampsia, liver failure or haemorrhage, stroke, death (rare) and long-term cardiovascular morbidity [4] [6]-[13]. Foetal and neonatal implications include foetal macrosomia, congenital abnormalities, stillbirth preterm delivery, foetal growth restriction, neonatal intensive care admission, hypoxia-neurologic injury, perinatal death, long-term cardiovascular mor- 
bidity associated with low birthweight (foetal origin of adult disease) [4] [7] [12] [14]. Long term implications include increase likelihood of being obese in subsequent pregnancies and obesity in offsprings [9].

During the period of the study from $1^{\text {st }}$ December 2017 to $31^{\text {st }}$ December 2018, there were a total of 4198 deliveries and 145 women were morbidly obese. The prevalence of morbid obesity in this population was $3.45 \%$. This is similar to the prevalence of $2 \%$, which was noted by Marie I. Cedergreen in her paper on "maternal morbid obesity and the risk of adverse pregnancy outcome" [10].

The audit demonstrates that obesity in pregnancy is associated with adverse maternal, foetal and neonatal outcome.

Pre-pregnancy risk associated with obesity and noted in this audit were previous miscarriages, and this was the most common risk. Other risks associated with the morbidly obese were polycystic ovarian syndrome, diabetes and hyperprolactinemia. Many studies have shown a direct association between obesity and miscarriages in spontaneous conception and assisted pregnancies, although the mechanism for this is poorly understood [4] [7] [11] [12]. Lashen et al. in their paper on "obesity is associated with increased risk of first trimester and recurrent miscarriages: matched case-control study" reported an odds ratio for spontaneous abortion of 1.2 (95\% CI 1.01 to 1.46$)$ for obese women (BMI > 30 $\mathrm{kg} / \mathrm{m}^{2}$ ) [15]. This study further strengthens the association between miscarriages and obesity.

Several antenatal outcomes have been associated with obesity in pregnancy. In this audit, the complications that were found in morbidly obese women were gestational hypertension, gestational diabetes, suspected fetal macrosomia, intrauterine growth restriction, preeclampsia and placenta previa. These complications are consistent with findings from R Scoot-Pillai and colleagues on the impact of body mass index on maternal and neonatal outcomes: a retrospective study in a UK obstetric population, 2004-2011. Other studies have also confirmed this [1] [2] [4] [7] [9] [12] [16] [17] [18] [19]. Furthermore, Vaswani and associates in their study of "pregnancy outcomes in a population with highprevalence of obesity: How bad is it?" revealed that obese women were about 5 times more likely to develop hypertensive disorders of pregnancy $(\mathrm{OR}=4.97$, $95 \% \mathrm{CI}, 1.35-18.33, p=0.016)$ and 4 times more likely to develop gestationaldiabetes [20].

Obesity in pregnancy is associated with increased risk of operative delivery, and interestingly this audit revealed that morbidly obese women had more normal births than forceps and caesarean section. This is not the usual case, and although the causal relationship between obesity and operative delivery remains unclear, several studies have documented an increase in operative deliveries especially in the morbidly obese compared to the none obese [6] [11] [21].

Intrapartum complications such as induced labour, slow labour, increased risk of caesarean section, shoulder dystocia and perineal tears are increased in obese women and especially in the morbidly obese women, and interestingly this audit 
did not reveal any adverse intrapartum outcome in the morbidly obese women. This may be due to the small sample size. On the contrary, a study by Permanand and colleagues in their "comparative study of obstetric outcome in overweight and obese women" found intrapartum complications such as increased risk of caesarean section, difficult anaesthesia, excess blood loss and prolonged surgery was more in this group [1]. This has also be confirmed by several other studies and publications [1] [2] [3] [11] [20].

This audit also revealed that certain postpartum complications are more common in morbidly obese women. Most of the patients in the audit had no complications and the complications discovered were, postpartum haemorrhage, postpartum hypertension, and wound dehiscence and wound infections. This has been highlighted by several studies on this subject [2] [6] [7] [12] [13] [14] [22].

Neonatal concerns and outcome was also was considered, and the audit found that the majority of the morbidly obese parturient (77\%) had no foetal or neonatal complications. Of the complications, $18 \%$ were macrosomic babies, $3 \%$ had congenital abnormalities and stillbirth in $2 \%$, and $5 \%$ of babies had of low $5^{\text {th }}$ minute Apgar score of less than 7. This is also corroborated by several studies [9]

Box 1. Key assurances, areas of development, negative issues and recommendations.

\section{Key Assurances:}

Proper documentation in the antepartum, intrapartum and postpartum periods

Good folic acid nutritional supplementation

Compliant with antenatal screening for the women

Screening for prenatal complications such as gestational diabetes was good

Good intrapartum and multidisciplinary care of maternal foetal and neonatal outcome in morbidly obese women

Excellent postpartum support for breastfeeding and contraception

Key Areas for development:

Easy access to Medway Maternity for data collection but significant delay in note retrieval for data collection

Key issues arising from the analysis that negatively affects patient care:

Some missing notes and missing sheets inpatient case notes

Weight and BMI not recorded in some notes

Some of the patients were not offered Vit D nutritional supplementation

None compliance in the referral of some of the women to the anaesthetist for review antepartum

\section{Recommendations:}

To improve preconception care and counselling for weight reduction to improve pregnancy outcome

To appropriately corroborate and timely referrals to other specialities such as endocrinology and anaesthetist

To properly file patients note and sheets as this will improve patient safety

To offer recommended nutritional supplements

To keep up with the level and standard of care for morbidly obese women as per national guidelines

For a reaudit in one year 
[13] [14]. Joan Crane and associates in their study of maternal and perinatal outcomes of extreme obesity in pregnancy discovered that neonatal complications including macrosomia, neonatal metabolic abnormalities, neonatal intensive care admission, and stillbirth, were also more frequent in obese women even after adjusting for maternalage, parity, smoking, partner status, and gestational age [8].

When comparing with the auditable criteria in the RCOG guidelines, it was found that the standard of care was $92.67 \%$ compliant with recommended standards. The compliance is very impressive with room for improvement. The key areas of assurances and development, as well as recommendations, are displayed in Box 1.

\section{Conclusion}

Obesity is widely known to be associated with adverse outcome in pregnancy, and this is said to be more conspicuous in the morbidly obese women. This audit revealed and corroborated with existing studies that morbidly obese women in our obstetric population were at risk of some of the unfavourable pregnancy outcomes. Managing these complications can be quite challenging and usually requires multidisciplinary input across a range of specialities. In trying to reduce some of these burdens, it is imperative that preconception counselling and care to achieve the ideal body weight before pregnancy with a healthy diet and lifestyle should be encouraged and emphasized. Also, optimizing medical and obstetric comorbidities such as gestational diabetes, and hypertension should also be a goal. Furthermore, early recognition and treatment of the complications will go a long way in improving pregnancy outcomes and minimizing the implications of the weight and obesity-related comorbidities in pregnancy.

\section{Conflicts of Interest}

The authors of this manuscript declare there is no conflict of interest.

\section{References}

[1] Shah, P.K., Chaudhari, H.K. and Garg, S. (2018) Comparative Study of Obstetric Outcome in Overweight and Obese Pregnant Women. International Journal of Reproduction, Contraception, Obstetrics and Gynecology, 7, 3199. https://doi.org/10.18203/2320-1770.ijrcog20183317

[2] Denison, F.C., Aedla, N.R., Keag, O., Hor, K., Reynolds, R.M., Milne, A., et al. (2019) Care of Women with Obesity in Pregnancy: Green-Top Guideline No. 72. BJOG: An International Journal of Obstetrics and Gynaecology, 126, 62-106. https://doi.org/10.1111/1471-0528.15386

[3] Ma, R.C.W., Schmidt, M.I., Tam, W.H., McIntyre, H.D. and Catalano, P.M. (2016) Clinical Management of Pregnancy in the Obese Mother: Before Conception, during Pregnancy, and Post Partum. The Lancet Diabetes and Endocrinology, 4, 1037 1049. https://doi.org/10.1016/S2213-8587(16)30278-9

[4] Thanoon, O., Gharaibeh, A. and Mahmood, T. (2015) The Implications of Obesity on Pregnancy Outcome. Obstetrics, Gynaecology and Reproductive Medicine, 25, 
102-105. https://doi.org/10.1016/j.ogrm.2015.01.008

[5] Lumsden, M.A. and Hor, K. (2015) Impact of Obesity on the Health of Women in Midlife. The Obstetrician \& Gynaecologist, 17, 201-208.

https://doi.org/10.1111/tog.12199

[6] Stewart, F.M., Ramsay, J.E. and Greer, I.A. (2009) Obesity: Impact on Obstetric Practice and Outcome. The Obstetrician \& Gynaecologist, 11, 25-31. https://doi.org/10.1576/toag.11.1.25.27465

[7] Chodankar, R., Middleton, G., Lim, C. and Mahmood, T. (2018) Obesity in Pregnancy. Obstetrics, Gynaecology and Reproductive Medicine, 28, 53-56.

https://doi.org/10.1016/j.ogrm.2017.11.003

[8] Crane, J.M.G., Murphy, P., Burrage, L. and Hutchens, D. (2013) Maternal and Perinatal Outcomes of Extreme Obesity in Pregnancy. Journal of Obstetrics and Gynaecology Canada, 35, 606-611. https://doi.org/10.1016/S1701-2163(15)30879-3

[9] Scott-Pillai, R., Spence, D., Cardwell, C.R., Hunter, A. and Holmes, V.A. (2013) The Impact of Body Mass Index on Maternal and Neonatal Outcomes: A Retrospective Study in a UK Obstetric Population, 2004-2011. BJOG: An International Journal of Obstetrics and Gynaecology, 120, 932-939. https://doi.org/10.1111/1471-0528.12193

[10] Cedergren, M.I. (2004) Maternal Morbid Obesity and the Risk of Adverse Pregnancy Outcome. Obstetrics and Gynecology, 103, 219-224. https://doi.org/10.1097/01.AOG.0000107291.46159.00

[11] Mission, J.F., Marshall, N.E. and Caughey, A.B. (2015) Pregnancy Risks Associated with Obesity. Obstetrics and Gynecology Clinics of North America, 42, 335-353. https://doi.org/10.1016/j.ogc.2015.01.008

[12] Davies, G.A.L., Maxwell, C. and McLeod, L. (2018) Obesity in Pregnancy. Journal of Obstetrics and Gynaecology Canada, 40, 630-639. https://doi.org/10.1016/j.jogc.2018.05.018

[13] Dutton, H., Borengasser, S.J., Gaudet, L.M., Barbour, L.A. and Keely, E.J. (2018) Obesity in Pregnancy: Optimizing Outcomes for Mom and Baby. Medical Clinics of North America, 102, 87-106. https://doi.org/10.1016/j.mcna.2017.08.008

[14] Gunatilake, R.P. and Perlow, J.H. (2011) Obesity and Pregnancy: Clinical Management of the Obese Gravida. American Journal of Obstetrics and Gynecology, 204, 106-119. https://doi.org/10.1016/j.ajog.2010.10.002

[15] Lashen, H., Fear, K. and Sturdee, D.W. (2004) Obesity Is Associated with Increased risk of First Trimester and Recurrent Miscarriage: Matched Case-Control Study. Human Reproduction, 19, 1644-1646. https://doi.org/10.1093/humrep/deh277

[16] Roman, H., Robillard, P., Hulsey, T.C., Laffitte, A., Kouteich, K., Marpeau, L., et al. (2007) Obstetrical and Neonatal Outcomes in Obese Women. West Indian Medical Journal, 56, 421-426.

[17] Rayis, D.A., Abbaker, A.O., Salih, Y. and Adam, I. (2011) Obesity and Pregnancy Outcome in Khartoum, Sudan. International Journal of Gynecology and Obstetrics, 113, 160-161. https://doi.org/10.1016/j.ijgo.2010.12.008

[18] Rowlands, I., Graves, N., de Jersey, S., McIntyre, H.D. and Callaway, L. (2010) Obesity in Pregnancy: Outcomes and Economics. Seminars in Fetal and Neonatal Medicine, 15, 94-99. https://doi.org/10.1016/j.siny.2009.09.003

[19] Bianchi, C., de Gennaro, G., Romano, M., Aragona, M., Battini, L., Del Prato, S., et al. (2018) Pre-Pregnancy Obesity, Gestational Diabetes or Gestational Weight Gain: Which Is the Strongest Predictor of Pregnancy Outcomes? Diabetes Research and Clinical Practice, 144, 286-293. https://doi.org/10.1016/j.diabres.2018.08.019 
[20] Vaswani, P.R. and Balachandran, L. (2013) Pregnancy Outcomes in a Population with High Prevalence of Obesity: How Bad Is It? Clinical Epidemiology and Global Health, 1, 5-11. https://doi.org/10.1016/j.cegh.2012.11.006

[21] Counseling, W.L., Schummers, L., Hutcheon, J.A. and Bodnar, L.M. (2015) Risk of Adverse Pregnancy Outcomes by Prepregnancy Body Mass Index: A PopulationBased Study to Inform Prepregnancy. Obstetrics \& Gynecology, 125, 133-143. https://doi.org/10.1097/AOG.0000000000000591

[22] Aviram, A., Hod, M. and Yogev, Y. (2011) Maternal Obesity: Implications for Pregnancy Outcome and Long-Term Risks: A Link to Maternal Nutrition. International Journal of Gynecology and Obstetrics, 115, S6-S10.

https://doi.org/10.1016/S0020-7292(11)60004-0 